\title{
Formação em Odontologia: O Papel das Instituições de Ensino na Prevenção do Acidente com Exposição a Material Biológico
}

\section{FORMACIÓN EN ODONTOLOGIAA: EL PAPEL DE LAS INSTITUCIONES DE ENSENNANZA EN LA PREVENCIÓN DE ACCI- DENTES CON EXPOSICIÓN A MATERIAL BIOLÓGICO}

\author{
Silvana Maria Ramos Lages ${ }^{1}$, Aldenir Feitosa dos Santos², Francisco Feliciano da Silva Junior ${ }^{3}$, João Gomes da Costa ${ }^{4}$ \\ 1. Mestra em pesquisa em saúde, Médica do Trabalho da Universidade Federal de Alagoas, Brasil. \\ 2. Doutora em Química e Biotecnologia, Faculdade de Medicina - Centro Universitário CESMAC, Maceió Alagoas, Brasil. \\ 3. Doutor em Medicina Veterinária, professor do Mestrado Profissional Pesquisa em Saúde do Centro Universitário CESMAC, Maceió Alagoas, Brasil. \\ 4.Doutor em Biotecnologia, Pesquisador - Universidade Federal de Alagoas, Brasil.
}

\section{RESUMO}

O objetivo do estudo foi analisar o conhecimento e condutas de alunos de graduação em odontologia de duas instituições de ensino, uma pública outra privada, frente à ocorrência de acidente com exposição a material biológico e controle de infecção, como também discutir o papel das instituições de ensino nesse contexto. Trata-se de um estudo transversal, descritivo de abordagem quantitativa, no qual foi aplicado um questionário semiestruturado, autoaplicável e padronizado a 224 alunos. Foram exploradas: I- medidas de proteção, II- ocorrência de acidentes e conhecimento das condutas pós-acidente III- conhecimento, percepção do risco e esclarecimentos formalmente preconizados. Os resultados demonstraram vulnerabilidade dos alunos quanto à exposição ao material biológico potencialmente contaminado e que ambas as instituições necessitam reavaliar suas ações referentes ao risco biológico e prevenção de acidentes. A instituição que mantem um comitê de biossegurança e possui protocolo, bem divulgado, em caso de acidentes com exposição a material biológico, apresentou melhores resultados quanto ao uso do equipamento de proteção individual, notificação do acidente e testagem da imunidade após vacina para hepatite B. 0 estudo concluiu que as instituições de ensino têm participação importante e devem estabelecer regras e estratégias de intervenção a fim de reduzir os riscos.

(Ramos Lages, S. M, Santos, A. F, Silva Júnior, F. F,Costa, J. G, 2015. Formação em Odontologia: 0 Papel das Instituições de Ensino na Prevenção do Acidente com Exposição a Material Biológico. Cienc Trab. Sep-Dic; 17 [54]: 182-187).

Descritores: ACIDENTES E EVENTOS BIOLÓGICOS; PREVENÇÃO DE ACIDENTES; EDUCAÇÃO EM ODONTOLOGIA.

\section{RESUMEN}

Estudiantes de odontología presentan vulnerabilidad a sufrir exposición accidental a material biológico. El objetivo de este estudio fue analizar el conocimiento y el comportamiento de estudiantes de odontología de dos instituciones educacionales, una pública y otra privada, contra la ocurrencia de accidentes con exposición a material biológico y control de infección, además de la discusión del rol de las instituciones educacionales en este contexto.

Este es un estudio transversal, descriptivo de enfoque cuantitativo, en el cual se aplicó un cuestionario semi-estructurado, se autoaplicó y estandarizó a 224 estudiantes. Se exploró: I- Medidas de protección, II- Ocurrencia de accidentes y conocimiento del comportamiento post-accidentes. III- Conocimiento, percepción de riesgo y clarificaciones recomendadas formalmente. Los resultados demostraron la vulnerabilidad de los estudiantes en relación con la exposición a material biológico potencialmente contaminado y que ambas instituciones necesitan reevaluar sus acciones relativas a los riesgos biológicos y prevención de accidentes. La institución que mantiene un Comité de Bioseguridad y tiene un protocolo, bien divulgado, en caso de accidentes con exposición a material biológico, presentó mejores resultados en el uso de equipamiento protector, notificación de accidentes y pruebas de inmunidad después de vacunas contra la hepatitis B. El estudio concluyó que las instituciones educacionales tienen interés sustancial y establecerán reglas e intervenciones estratégicas para reducir los riesgos.

Palabras clave: ACCIDENTES Y EVENTOS BIOLÓGICOS; PREVENCIÓN DE ACCIDENTES, EDUCACIÓN, DENTAL.

Correspondencia / Correpondence:

Silvana Maria Ramos Lages

Hospital Universitário Prof. Alberto Antunes,

Universidade Federal de Alagoas -

UFAL - SIASS (Medicina do Trabalho).

Av. Lourival de melo mota $\mathrm{S} / \mathrm{N}$ -

Tabuleiro do Martins, Maceió - Al, Brasil.

Tel: (82) 3322-1329

e-mail: sramoslages@gmail.com

Recibido: 30 de Septiembre de 2015 /Aceptado: 02 de Noviembre de 2015

\section{INTRODUÇ̃̃O}

A consciência de que os profissionais de saúde estão expostos a agentes transmitidos pelo sangue, surgiu nos anos 70 com o aumento de profissionais infectados pelo vírus da Hepatite B (VHB) e se concretizou nos anos 80 com o inicio dos casos de AIDS. ${ }^{1}$

As exposições que podem trazer riscos de transmissão ocupacional do HIV e dos vírus das hepatites B e C estão definidas como: percutâneas, quando há lesões provocadas por instrumentos perfurantes e cortantes; mucosas, quando há respingos envolvendo olhos, 
nariz ou boca; cutâneas, quando há contato com pele não integra e por mordeduras humanas, que são consideradas como exposição de risco quando envolvem a presença de sangue. ${ }^{2}$

Os virus da hepatite B (VHB), da hepatite C (VHC) e da AIDS (HIV) são os patógenos mais comumente transmitidos durante as atividades de assistência ao paciente. ${ }^{3}$ Considerando os acidentes percutâneos, estima-se, em média, que o risco de transmissão do HIV é de $0,3 \%$, para o VHC é de $1 \%$ a $10 \%$ e para o VHB é de até $40 \%{ }^{4}$

No Brasil o acidente com exposição a material biológico (AEMB) caracteriza-se como um evento de notificação compulsória desde 2004, definição que foi reafirmada em 2014. ${ }^{5}$ Nas situações em que não foi possivel evitar as exposições ocupacionais, condutas pósexposição podem prevenir infecções e devem ser adotadas. Para que se obtenha maior eficácia, as intervenções para profilaxia da infecção pelo HIV e hepatite B, necessitam ser iniciadas logo após a ocorrência do acidente. ${ }^{2}$ Joyce et $\mathrm{al}^{6}$ relataram que poucos casos de transmissão ocupacional do HIV foram reportados nos Estados Unidos, desde o final de 1990, o que foi atribuído, entre outras causas, à melhoria nas estratégias de prevenção e gestão da pósexposição.

Recursos devem ser utilizados para reduzir as exposições a material biológico, como as precauções padrão, as quais recomendam considerar todos os pacientes potencialmente contaminados quando houver possibilidade de contato com sangue e outras secreções. Dentre essas precauções se destacam: higiene das mãos, o uso de Equipamento de Proteção Individual (EPI), manuseio, transporte e descarte corretos de artigos perfurocortantes e a imunização. ${ }^{7}$ A vacina para a hepatite $B$ tem esquema clássico de três doses $(0,1,6$ meses) necessário para a imunização, contudo, aproximadamente $10 \%$ a $20 \%$ dos indivíduos vacinados não alcançam os títulos protetores de anticorpos. ${ }^{2}$

As características da atividade do cirurgião-dentista (CD), tais como o pequeno campo de visualização em que atua, os procedimentos invasivos que realiza, a utilização de instrumentos perfurocortantes de alta rotação e ultrassônicos, que condicionam a formação de aerossóis e respingos e a grande proximidade física do paciente, favorecem a ocorrência de acidentes. ${ }^{8}$ Estudo conduzido por Zhang et $\mathrm{al}^{9}$ evidenciou que os estudantes de odontologia apresentam um maior risco de sofrer exposição acidental envolvendo material biológico quando comparados a outros estudantes da área da saúde. Os acidentes são mais frequentes em estudantes de odontologia possivelmente porque ainda estão em processo de aprendizagem, e consequentemente possuem pouca destreza e habilidade no manuseio dos materiais. ${ }^{10}$

A biossegurança não se resume somente a normas de prevenção e controle; a sua dimensão científica requer dos indivíduos uma formação educacional adequada para a compreensão e execução dos seus objetivos. ${ }^{11} \mathrm{Na}$ odontologia, os acadêmicos têm sido apontados como o grupo para o qual a educação em biossegurança e o controle de infecção cruzada são imprescindiveis para correto treinamento e cumprimento dos protocolos rotineiramente. ${ }^{12}$

Sabe-se que a aderência de estudantes às normas de biossegurança se intensifica com obrigatoriedade e a fiscalização, no entanto, qual a real situação nas Instituições de Ensino? Até que ponto o cumprimento de normas e as condutas preventivas dos alunos de odontologia se fundamentam no conhecimento sobre a exposição aos riscos biológicos? Este estudo foi realizado com o objetivo de examinar o conhecimento e condutas de alunos de graduação em odontologia de duas instituições de ensino superior (IES), frente ao AEMB, como também constatar as diferenças entre as instituições e comparar com as medidas preventivas implantadas. Neste contexto, podem-se ajustar treinamentos, priorizar condutas e reavaliar medidas de biossegurança e prevenção.

\section{MATERIAIS E MÉTODOS}

Esta pesquisa obteve aprovação do Comitê de Ética em Pesquisa do Centro Universitário CESMAC sob o número 655.175, de acordo com as diretrizes da resolução CNS/MS 466/12.

Delineou-se um estudo transversal, descritivo, com abordagem quantitativa, realizado com estudantes do curso de odontologia do Centro Universitário CESMAC e da Universidade Federal de Alagoas (UFAL), aqui codificadas como IES(A) e IES(B), respectivamente, na cidade de Maceió - Al, Brasil. 0 número de alunos matriculados nas duas IES nos meses de maio a julho de 2014 , com atividades na clínica odontológica ( $5^{\circ}$ ao $9^{\circ}$ períodos) correspondeu a 438 alunos, sendo 325 na IES(A) e 113 na IES(B). Consentiram participar da pesquisa 134 alunos da IES(A) e 90 alunos da IES(B).

Na IES(A) o conteúdo referente à biossegurança é ministrado na disciplina de microbiologia e imunologia no $3^{\circ}$ período e na disciplina de propedêutica clínica I no $4^{\circ}$ período. A disciplina de microbiologia e imunologia tem carga horária de 80 horas e propedêutica clínica I tem carga horária de 160 horas. Existe na faculdade um protocolo a seguir quando da ocorrência de AEMB e um comitê de biossegurança formado. Na IES(B) o conteúdo referente à biossegurança é ministrado no $4^{\circ}$ período na disciplina de fundamentos de enfermagem que tem carga horária de 30 horas. Existe na faculdade um protocolo a seguir quando da ocorrência de $\mathrm{AEMB}$ e não há comitê de biossegurança formado.

0 instrumento de coleta de dados foi um questionário semiestruturado autoaplicável e padronizado, elaborado para o objetivo da pesquisa e pré-testado em 65 graduandos de odontologia não participantes da pesquisa. 0 questionário abordou: I - medidas de proteção, II - ocorrência de acidentes e conhecimento das condutas pós-acidente III - conhecimento, percepção do risco e esclarecimentos formalmente preconizados. A coleta de dados ocorreu nos meses de abril a junho de 2014 com a aplicação do questionário realizada em sala de aula e recolhido em seguida. Todos os alunos participantes foram previamente informados sobre os objetivos da pesquisa e assinaram o termo de consentimento livre e esclarecido, com a garantia do sigilo da identificação pessoal.

Os dados foram tabulados em planilha eletrônica e analisados através de estatística descritiva e inferencial ao nível de 5\% de significância por meio do programa GENES. 0 Teste do qui-quadrado de Pearson foi aplicado para buscar diferenças estatisticamente significantes entre as duas IES e entre os períodos de cada instituição.

\section{RESULTADOS}

Através da distribuição dos pesquisados por gênero e faixa etária, foi possivel verificar que a maioria tinha entre 18 a 25 anos de idade em ambas as instituições, 79,5\% na IES (A) e $81 \%$ na IES(B), havendo predominância do gênero feminino $71,6 \%$ na IES(A) e 59\% na IES(B).

Na Tabela 1 apresentam-se os resultados referentes às medidas utilizadas para reduzir a transmissão de agentes patógenos. 0 relato de sempre utilizar jaleco, luvas, máscara e gorro foi feito pela maioria dos alunos de ambas as IES, entretanto quanto à utilização de óculos 
Tabela 1.

Medidas utilizadas, para reduzir a transmissão de patógenos. Maceió, AL, 2014.

\begin{tabular}{|c|c|c|c|c|c|c|}
\hline \multirow[b]{2}{*}{ Uso de EPI } & \multicolumn{2}{|c|}{$\begin{array}{l}\text { IES (A) particular } \\
\text { Alunos }(n=134)\end{array}$} & \multicolumn{2}{|c|}{$\begin{array}{l}\text { IES (B) pública } \\
\text { Alunos }(n=90)\end{array}$} & $\chi 2^{*}$ & $P$ - valor \\
\hline & & & & & & \\
\hline Jaleco (sempre) & 132 & 98,50 & 88 & 97,77 & 0 & 1 \\
\hline Luvas (sempre) & 133 & 99,25 & 90 & 100 & 0,0119 & 0,9129 \\
\hline Máscara (sempre) & 132 & 98,50 & 87 & 96,66 & 0,0068 & 0,9340 \\
\hline Gorro (sempre) & 133 & 99,25 & 87 & 96,66 & 0,0189 & 0,8905 \\
\hline Óculos (sempre) & 125 & 93,28 & 61 & 67,77 & 4,224 & 0,0448 \\
\hline Óculos (às vezes) & 9 & 6,71 & 27 & 30 & 18,375 & $<0,0001$ \\
\hline \multicolumn{7}{|l|}{ Uso de EPI apropriado** } \\
\hline Luva grossa de borracha & 130 & 97,0 & 45 & 50 & 15,2328 & $<0,0001$ \\
\hline Luva - látex não estéril & 3 & 2,25 & 35 & 38,89 & 42,6298 & $<0,0001$ \\
\hline Luva - látex estéril & 1 & 0,75 & 3 & 3,33 & 2,0179 & 0,1554 \\
\hline Luva de qualquer tipo & 0 & 0 & 7 & 7,78 & 10,4222 & 0,0012 \\
\hline \multicolumn{7}{|l|}{ Vacina VHB } \\
\hline Recebeu três doses & 122 & 91,04 & 68 & 75,56 & 1,8418 & 0,1747 \\
\hline Não respondeu & 0 & 0 & 3 & 3,33 & 4,3846 & 0,0362 \\
\hline Não sabia no de doses & 3 & 2,24 & 9 & 10 & 5,8785 & 0,0153 \\
\hline $\begin{array}{l}\text { Avaliou imunidade após } \\
3 \text { doses da vacina VHB }\end{array}$ & $(n=122)$ & & $=68)$ & & & \\
\hline Sim & 113 & 92,62 & 14 & 20,59 & 34,68 & $<0,0001$ \\
\hline Não & 9 & 7,38 & 54 & 79,41 & 68,82 & $<0,0001$ \\
\hline
\end{tabular}

VHB - Virus da Hepatite B EPI- Equipamento de proteção Individual *Qui Quadrado $P<0,05$ ** Na limpeza de instrumentos e equipamentos contaminados.

de proteção, houve uma diferença estatisticamente significativa no relato de sempre usá-los, sendo maior na IES(A) $(93,28 \%)$, como também o relato de às vezes usá-los foi maior na IES(B) (30\%), este último com diferença bastante significativa ( $p<0,0001)$. A utilização de luvas emborrachadas de espessura grossa, apropriadas para realização da limpeza dos instrumentais, foi referida pela maioria dos alunos da IES(A) (97\%), enquanto que na IES(B) apenas 50\% dos alunos relataram fazer uso das luvas apropriadas $(p<0,0001) . \mathrm{Na}$ IES(B) 38,89\% dos alunos relataram usar luvas de látex não estéril ( $p$ $<0,0001$ ) e ainda e $7,78 \%$ referiram usar luvas de qualquer tipo para o mesmo procedimento ( $\mathrm{p}=0,0012)$.

Quanto à situação vacinal para a hepatite $\mathrm{B}$, a maioria dos alunos das duas IES relatou ter recebido o esquema completo de três doses, porem houve uma diferença significativa no número de alunos que não sabiam quantas doses da vacina tinham recebido, o qual foi bem maior na IES(B) ( $p=0,0153)$.

Tabela 2.

Medidas preventivas adotadas relativas à higienização das mãos, Maceió, $A L, 2014$.

\begin{tabular}{|c|c|c|c|c|c|c|}
\hline Itens & $\begin{array}{c}\text { IES }(A \\
\text { Alunos } \\
n\end{array}$ & $\begin{array}{c}\text { articular } \\
1=134) \\
\%\end{array}$ & $\begin{array}{l}\text { IES } \\
\text { Alun } \\
n\end{array}$ & $\begin{array}{c}\text { pública } \\
(n=90) \\
\%\end{array}$ & $\chi 2^{*}$ & $P$ - valor \\
\hline \multicolumn{7}{|l|}{ Higiene das mãos } \\
\hline $\begin{array}{l}\text { Ao iniciar atendimento } \\
\text { (às vezes) }\end{array}$ & 12 & 8,95 & 18 & 20 & 5 & 0,0253 \\
\hline $\begin{array}{l}\text { Após procedimentos com } \\
\text { pacientes (às vezes) }\end{array}$ & 15 & 11,2 & 18 & 20 & 8,8081 & 0,08 \\
\hline $\begin{array}{l}\text { Antes de calçar as luvas } \\
\text { (às vezes) }\end{array}$ & 44 & 32,83 & 42 & 46,66 & 2,7984 & 0,0943 \\
\hline $\begin{array}{l}\text { Depois de retirar luvas } \\
\text { (às vezes) }\end{array}$ & 24 & 17,91 & 25 & 27,78 & 2,4795 & 0,1153 \\
\hline $\begin{array}{l}\text { Após contato com objetos } \\
\text { e superficies (sempre) }\end{array}$ & 93 & 69,40 & 43 & 47,77 & 4,1469 & 0,0417 \\
\hline $\begin{array}{l}\text { Após contato com objetos } \\
\text { e superficies (às vezes) }\end{array}$ & 39 & 29,10 & 44 & 48,88 & 5,6874 & 0,0170 \\
\hline
\end{tabular}

Quanto a higienização das mãos (Tabela-2), com água e sabão ou preparação alcoólica, ao iniciar o atendimento, foi referido apenas (às vezes) por $8,95 \%$ dos alunos da IES(A) e $20 \%$ da IES(B) (p = 0,0253). Após contato com objetos inanimados e superfícies imediatamente próximas ao paciente, $69,4 \%$ dos alunos da IES(A) e 47,77\% da IES(B) informaram realizar sempre a higienização das mãos ( $\mathrm{p}=0,0417)$. Para a mesma situação mencionada anteriormente $29,10 \%$ dos alunos da IES(A) e $48,88 \%$ da IES(B) informaram que apenas às vezes procediam a higienização das mãos ( $p$ $=0,0170$ ). A prática da higienização das mãos, antes de calçar as luvas, foi informada apenas (às vezes) por 32,83\% dos alunos da IES(A) e 46,66\% da IES(B), assim como a higienização das mãos após retirada das luvas foi informada apenas (às vezes) por $17,91 \%$ dos alunos da IES(A) e 27,78\% da IES(B).

Observou-se diferença estatisticamente significativa quanto ao número de acidentes com exposição a material biológico. Ter sofrido um a dois acidentes foi informado por 7,46\% dos alunos da IES(A) e $20 \%$ da IES(B) ( $p=0,0087$ ). Nenhum aluno da IES(A) fez referencia a ter sofrido três ou mais acidentes e $4,44 \%$ dos alunos da IES(B) referiram três ou mais acidentes ( $p=0,0143$ ), conforme (Tabela - 3). Das 10 ocorrências de acidentes relatadas na IES(A), 3 não foram notificadas. Um motivo de não ter notificado foi já ser vacinado e os outros foram por não achar necessário. $\mathrm{Na}$ IES(B) das 28 ocorrências relatadas 17 (60,71\%) não foram notificadas. Treze ocorrências não foram notificadas pelo motivo de não achar necessário; os outros motivos alegados foram: já ser vacinado, dificuldade para registro do acidente e porque a lesão causada foi superficial.

Conforme apresentado na (Tabela 3) 41,04\% dos alunos da IES(A) informaram ser o HIV o agente com maior risco de transmissão na ocorrência de um AEMB. 0 mesmo agente foi relatado por 17,78\% dos alunos da IES (B) $(p<0,05)$. A maioria dos alunos da IES(B) informou, corretamente, ser o VHB o agente com maior risco de transmissão, enquanto na IES(A), apenas 32,84\% dos alunos relataram o VHB como o agente com maior risco $(p<0,05)$. Com relação à existência de vacina ou outra medida profilática tipo imunoglobulina ou quimioprofilaxia para o VHC a maioria dos alunos 58,96\% da IES(A) e 53,33\% da IES(B) informou não saber responder.

Outra questão investigada foi quais são os patógenos que devem ser pesquisados após um AEMB, segundo o Ministério da Saúde. 0 HIV

Tabela 3.

Respostas relativas à ocorrência de acidente com exposição a material biológico e conhecimentos adquiridos. Maceió, AL, 2014.

\begin{tabular}{|c|c|c|c|c|c|c|}
\hline & \multicolumn{2}{|c|}{$\begin{array}{l}\text { IES }(A) \text { particular } \\
\text { Alunos }(n=134)\end{array}$} & \multicolumn{2}{|c|}{$\begin{array}{l}\text { IES (B) pública } \\
\text { Alunos }(n=90)\end{array}$} & $\chi^{2}$ * & $P$ - valor \\
\hline \multicolumn{7}{|c|}{ Ocorrência de acidentes } \\
\hline Um a dois & 10 & 7,46 & 18 & 20 & 6,8809 & 0,0089 \\
\hline Três ou mais & 0 & 0 & 4 & 4,44 & 10,4222 & 0,0012 \\
\hline \multicolumn{7}{|c|}{ Agente com maior risco** } \\
\hline HIV & 55 & 41,04 & 16 & 17,78 & 9,0234 & 0,0026 \\
\hline VHC & 17 & 12,69 & 16 & 17,78 & 0,9898 & 0,3197 \\
\hline VHB & 44 & 32,84 & 52 & 57,78 & 8,0277 & 0,0046 \\
\hline Não sei & 13 & 9,70 & 6 & 6,66 & 0,5614 & 0,4536 \\
\hline Não respondeu & 5 & 3,73 & 0 & 0 & 3,3333 & 0,0678 \\
\hline \multicolumn{7}{|c|}{$\begin{array}{l}\text { Conhecimento de vacina } \\
\text { ou medida profilática/NHC }\end{array}$} \\
\hline Sim & 39 & 29,10 & 16 & 17,78 & 2,8131 & 0,094 \\
\hline Não & 16 & 11,94 & 24 & 26,67 & 6,5385 & 0,0105 \\
\hline Não sei & 79 & 58,96 & 48 & 53,33 & 0,3001 & 0,5838 \\
\hline Não respondeu & 0 & 0 & 2 & 2,22 & 2,9777 & 0,0844 \\
\hline
\end{tabular}

* Qui Quadrado $\mathrm{P}<0,05$ *VHB Vírus da hepatite B VHC Virus da hepatite C 
Tabela 4.

Caracteristicas dos acidentes com exposição a material biológico, relatados pela população estudada. Maceió, AL, 2014.

\begin{tabular}{|c|c|c|c|c|c|c|}
\hline & $\begin{array}{l}N^{\circ} \text { de } \\
\text { IES (A }\end{array}$ & $\begin{array}{l}\text { corrências } \\
(n=10)\end{array}$ & $\begin{array}{l}N^{\circ} \text { de } \\
\text { IES (B) }\end{array}$ & $\begin{array}{l}\text { ocorrências } \\
(n=28)\end{array}$ & s $\chi 2^{*}$ & $P$ - valor \\
\hline \multicolumn{7}{|l|}{ Tipo de exposição } \\
\hline Respingo pele integra & 1 & 10 & 1 & 3,57 & 0,6666 & 0,4142 \\
\hline Respingo em mucosa & 0 & 0 & 2 & 7,14 & 0,6666 & 0,4142 \\
\hline Perfuração cutânea & 9 & 90 & 25 & 89,28 & 0 & 1 \\
\hline \multicolumn{7}{|l|}{ Parte do corpo atingida } \\
\hline Olhos & 0 & 0 & 2 & 7,14 & 0,7152 & 0,3977 \\
\hline Mãos & 2 & 20 & 8 & 28,57 & 0,2072 & 0,6489 \\
\hline Dedos & 8 & 80 & 18 & 64,28 & 0,2628 & 0,6081 \\
\hline \multicolumn{7}{|l|}{ Momento da ocorrência } \\
\hline Durante atendimento & 6 & 60 & 20 & 71,42 & 0,1955 & 0,6585 \\
\hline Limpeza de instrumentos & 4 & 40 & 8 & 28,57 & 0,4444 & 0,5050 \\
\hline
\end{tabular}

* Qui Quadrado $\mathrm{P}<0,05$

foi o agente mais citado em ambas as instituições 44,11\% IES(A) e $44,28 \%$ na IES(B). 0 VHB obteve 13,52\% das citações na IES(A) e $17,14 \%$ na IES(B). As citações para o VHC totalizaram 12,35\% na IES(A) e apenas 5,71\% na IES(B). Não responderam a questão $20,14 \%$ dos alunos da IES(A) e 15,55\% da IES(B), como também $10,44 \%$ da IES(A) e $11,11 \%$ da IES(B) referiram não saber responder. Os resultados descritos a seguir referem-se às características dos AEMB sofridos em ambas as IES, (Tabela-4). 0 tipo de exposição com maior prevalência em ambas as IES foi a perfuração cutânea, 90\% na IES(A) e $89,28 \%$ na IES(B) e a parte do corpo atingida com maior prevalência foram os dedos com 80\% IES(A) e 64\% IES(B). 0 momento da ocorrência do acidente com maior prevalência foi durante o atendimento, 60\% IES(A) e 71,42\% IES(B).

A Tabela 5 expõe resultados relativos às orientações recebidas sobre biossegurança, prevenção e como proceder em caso de AEMB. A maioria, 98,51\% da IES(A) e 98,89\% da IES(B), informou ter recebido orientações, mas quanto ao conhecimento da existência de um protocolo a ser seguido, em caso de AEMB na instituição, observa-se que 96,27\% dos alunos da IES(A) e 60\% da IES(B) responderam $\operatorname{sim}(\mathrm{p}<0,05)$. Enquanto 15,56\% dos alunos da IES(B) e nenhum aluno da IES(A) respondeu que não existia um protocolo em sua instituição ( $\mathrm{p}<0,001)$. Não souberam responder $3,73 \%$ dos alunos da IES(A) e 23,33\% da IES(B) (p < 0,01).

\section{Tabela 5.}

Respostas quanto às orientações recebidas relativas à biossegurança, prevenção de acidentes e condutas na ocorrência de AEMB. Maceió, AL, 2014.

\begin{tabular}{|c|c|c|c|c|c|c|}
\hline \multirow[t]{2}{*}{ Itens } & \multicolumn{2}{|c|}{$\begin{array}{l}\text { IES (A) particular } \\
\text { Alunos }(n=134)\end{array}$} & \multicolumn{2}{|c|}{$\begin{array}{l}\text { IES (B) pública } \\
\text { Alunos }(n=90)\end{array}$} & \multirow[t]{2}{*}{$\chi 2 *$} & \multirow[t]{2}{*}{$P$ - valor } \\
\hline & & & & & & \\
\hline \multicolumn{7}{|c|}{ Conhecimento de protocolo na IES } \\
\hline Sim & 129 & 96,27 & 54 & 60 & 8,6688 & 0,0032 \\
\hline Não & 0 & 0 & 14 & 15,56 & 20,8444 & $<0,001$ \\
\hline Não sei & 5 & 3,73 & 21 & 23,33 & 17,8227 & $<0,001$ \\
\hline Não respondeu & 0 & 0 & 1 & 1,11 & 1,4888 & 0,2223 \\
\hline \multicolumn{7}{|c|}{ Recebeu orientação/biossegurança e AEMB } \\
\hline Sim & 132 & 98,51 & 89 & 98,89 & 0,0007 & 0,9775 \\
\hline Não & 2 & 1,49 & 1 & 1,11 & 0,0584 & 0,8089 \\
\hline \multirow[t]{2}{*}{ Itens } & \multicolumn{2}{|c|}{$\operatorname{IES}(A)(n=132)^{* *}$} & \multicolumn{2}{|c|}{ IES (B) $(n=89)^{*}$} & \multirow[t]{2}{*}{$\chi 2 *$} & \multirow[t]{2}{*}{$P$ - valor } \\
\hline & $n$ & & $n$ & & & \\
\hline \multicolumn{7}{|c|}{ Satisfação/conhecimentos adquiridos } \\
\hline Muito satisfeito & 28 & 21,21 & 6 & 6,74 & 7,0784 & 0,0078 \\
\hline Satisfeito & 90 & 68,18 & 51 & 57,30 & 0,8617 & 0,3532 \\
\hline Pouco satisfeito & 13 & 9,85 & 29 & 32,59 & 14,7658 & 0,0001 \\
\hline Insatisfeito & 1 & 0,76 & 3 & 3,37 & 2,0416 & 0,1530 \\
\hline
\end{tabular}

Como informação complementar, os alunos foram questionados sobre sua satisfação em relação aos conhecimentos adquiridos relativos à biossegurança, prevenção e como proceder em caso de AEMB. Quanto a este aspecto, 21,21\% dos alunos da IES(A) e $6,74 \%$ da IES(B) responderam que estavam muito satisfeitos ( $p<$ 0,05). Não houve diferença significativa, entre as duas IES em relação às alternativas satisfeito e insatisfeito. Com relação à alternativa (pouco satisfeito), foi observada uma diferença bem significativa, 9,85\% na IES(A) e 32,59\% na IES(B) ( $p<0,01$ ).

$\mathrm{Na}$ análise entre os períodos da IES(A) foi observado no $5^{\circ}$ período, quando perguntado quais são os patógenos que devem ser pesquisados após um AEMB, conforme o Ministério da Saúde, maior prevalência de alunos que informaram não saber a reposta $(\mathrm{p}<$ 0,05 ). Ainda na mesma questão, no $9^{\circ}$ periodo foi observada maior prevalência de alunos que responderam vírus da hepatite $\mathrm{A}(\mathrm{p}=$ $0,04)$.

Através da analise entre os períodos da IES (B), foi possivel observar no $8^{\circ}$ período, quanto ao uso apropriado do EPI para a limpeza de instrumentos e equipamentos contaminados, maior prevalência da resposta (luvas de látex estéreis) $(\mathrm{p}<0,05)$. Ainda na IES (B), quando perguntado se sabia da existência de um protocolo a ser seguido no caso de AEMB, o $9^{\circ}$ período apresentou maior prevalência de alunos que responderam não saber da existência de protocolo dessa natureza $(\mathrm{p}<0,002)$.

\section{DISCUSSÃO}

No presente estudo, quanto ao uso do EPI, foi observado que a IES(A) apresentou melhores resultados o que pode ser atribuído a uma maior exigência e conscientização do uso. Os óculos de proteção foram os mais negligenciados, chegando a 30\% na IES(B). Em pesquisa entre estudantes de odontologia, Rahman et al ${ }^{13}$ constataram que apenas 27\% dos estudantes utilizavam a proteção para os olhos, Wicker e Rabenau ${ }^{14}$ em pesquisa com dentistas e estudantes de odontologia na Alemanha, observaram que dos entrevistados 55,6\% não usavam óculos de proteção durante a exposição ocupacional. Ribeiro ${ }^{8}$ observou que a boca e o nariz foram as regiões menos atingidas nos acidentes, possivelmente pelo uso mais sistemático de máscaras, o que não ocorreu com os olhos por ser o uso de óculos de proteção uma prática ainda pouco incorporada nas atividades rotineiras em odontologia.

Nas instituições de ensino odontológico do Brasil, faz parte das atribuições dos alunos o preparo do instrumental a ser usado, ou seja, limpeza, secagem e acondicionamento, no entanto o método de limpeza predominante é o manual conforme Sasamoto. ${ }^{15} 0$ método manual aumenta o risco de acidentes com perfurocortante e o uso de luvas emborrachadas de espessura grossa é indicado para assegurar maior proteção. Na IES(A) 97\% dos alunos relataram usar sempre as luvas apropriadas enquanto na IES(B), apena 50\% dos alunos relataram fazer uso dessas luvas. Outro estudo de Pimentel et $\mathrm{al}^{16}$ com alunos de odontologia apresentou uma prevalência ainda menor quanto ao uso das luvas apropriadas, pois constatou que apenas $2,5 \%$ dos alunos faziam uso de luvas emborrachadas para este fim, enquanto 91,2\% deles realizavam a limpeza com luvas de procedimento e 6,2\% não usavam nenhuma proteção. 0 que revela que o momento da limpeza do instrumental deve ser bem inspecionado e exigido o uso do EPI apropriado. Como demonstrado pelos dados, a maioria dos alunos de ambas as IES tinham recebido o esquema completo da vacina contra a hepa- 
tite B, no entanto, na IES(B) 79,41\% dos alunos não realizaram a confirmação sorológica da imunização pela realização do antiHBs, o que pode ser resultado de falta de conscientização e exigência por parte da IES. A confirmação da imunidade tem relação direta com a segurança em um possível acidente, uma vez que o acidentado pode não apresentar títulos protetores de anticorpos. A não confirmação da imunidade também foi observada por Matsuda et $\mathrm{al}^{17}$ em pesquisa feita com cirurgiões-dentistas de São Paulo, Brasil, na qual apenas 65,85\% dos vacinados tinham avaliado a imunidade. Em estudo com acadêmicos de odontologia Pinelli et $\mathrm{al}^{12}$ também observaram que $71,4 \%$ dos vacinados não haviam realizado a avaliação da imunidade. Outro aspecto revelado pelos dados foi que $10 \%$ de alunos da IES(B) não sabiam quantas doses da vacina contra a hepatite B tinham recebido, fato que demonstra pouca atenção para com a situação vacinal.

As luvas para ser uma barreira eficaz que protege completamente e impede a propagação de microrganismos têm imperfeições microscópicas, de modo que lavar as mãos é essencial. ${ }^{18}$ Quanto à higienização das mãos antes de calçar e após retirar as luvas, houve uma prevalência considerável de alunos, em ambas as IES, que informaram realizar a higienização apenas às vezes, o que demonstra a necessidade de maior conscientização em ambas as IES. Da mesma forma Rosental et $\mathrm{al}^{19}$, em um estudo com CD, observaram que 20\% dos profissionais participantes da pesquisa não tinham o hábito de lavar as mãos antes de usar luvas. Em outro estudo realizado por Vasconcelos et $\mathrm{al}^{20}$ com alunos de odontologia, foi observado que 70,9\% dos alunos não faziam a higienização das mãos antes dos procedimentos e 34,03\% não realizaram a higienização após o término do atendimento.

Quanto à ocorrência de $\mathrm{AEMB}$, houve uma maior prevalência na IES(B). Os dados da IES(B) são semelhantes à pesquisa realizada por Orestes-Cardoso et $\mathrm{al}^{21} \mathrm{em}$ duas IES, na qual foi constatado que $25,3 \%$ dos alunos haviam sofrido acidentes. A notificação do acidente não ocorreu em 30\% dos alunos da IES(A) e em 60,71\% da IES(B), o resultado encontrado na IES(B) está próximo ao encontrado por Machado-Cavalhais et $\mathrm{al}^{22} \mathrm{em}$ pesquisa com estudantes de odontologia, com resultado de 71,9\% de subnotificação. Younai et $\mathrm{al}^{23}$ em pesquisa realizada com alunos de odontologia também encontraram resultado semelhante, 70\% de subnotificação.

0 fato de mais de $80 \%$ dos acidentes ocorridos em ambas as instituições serem percutâneo coincide com outros estudos como o de Garcia, Blank ${ }^{24}$ e Sasamoto. ${ }^{15}$ Quanto à região do corpo atingida na ocorrência do acidente as mais referidas, em ambas as instituições, foram dedos e mãos. Os olhos foram relatados por 7,14\% dos alunos da IES(B) e não foi relatado na IES(A). 0 uso dos óculos de proteção apenas às vezes foi referido por $30 \%$ dos alunos da IES(B) e apenas 6,71\% da IES(A), o que pode explicar o resultado encontrado. No estudo realizado por Ribeiro ${ }^{8}$, olhos, dedos e mãos foram as regiões mais referidas. 0 momento da ocorrência do acidente com maior referência foi durante o atendimento ao paciente em ambas as instituições e coincide com o estudo de Myers et $\mathrm{al}^{25}$

Não existe nenhuma medida específica eficaz para a redução do risco de infecção pelo VHC, após exposição ocupacional. 0 único fator de eliminação desse risco é a prevenção do próprio acidente. ${ }^{2}$ Quando indagado se sabia da existência de medida especifica eficaz para a redução do risco de transmissão do VHC, a maioria $(58,96 \%)$ dos alunos da IES(A) não sabiam responder ou responderam sim $(29,10 \%)$, enquanto na IES(B) esses números correspon- deram respectivamente a $(53,33 \%)$ e $(17,78 \%)$. Na alternativa (não) houve uma diferença significativa, com 26,67\% dos alunos da IES(B) e $11,94 \%$ da IES(A). Foi constatado na IES(B) um maior número de alunos que responderam corretamente, entretanto é possivel observar que em ambas as IES os alunos não demonstraram conhecimento aceitável sobre o VHC.

Quando questionado sobre o agente com maior risco de transmissão na ocorrência de $\mathrm{AEMB}$, o HIV obteve maior prevalência na IES(A), por outro lado na IES(B) o VHB, que seria a resposta correta, obteve maior prevalência. As diferenças estatisticamente significativas revelaram que os alunos da IES(B) tinham melhor conhecimento sobre o agente com maior risco de transmissão. A deficiência do conhecimento dos estudantes de odontologia e de outras áreas da saúde acerca de patógenos veiculados pelo sangue tem sido discutida. Zhang et $\mathrm{al}^{9}$ destacaram, em estudo feito com estudantes da área da saúde, que o VHC era o patógeno menos conhecido.

Quando perguntado quais os patógenos que devem ser pesquisados após um AEMB, segundo o Ministério da Saúde, o HIV foi o mais referido em ambas as instituições 44,11\% IES(A) e 44,28\% na IES(B). O VHC obteve apenas 12,35\% das citações na IES(A) e $5,71 \%$ na IES(B). Destaca-se que não responderam a questão ou não sabiam 30,58\% dos alunos da IES(A) e $26 \%$ da IES(B). Dessa forma se constata a necessidade de que o conhecimento dos patógenos veiculados pelo sangue e com maior transmissibilidade seja aprimorado.

Não foi relatado conhecimento adequado dos alunos da IES(B) quanto à existência de um protocolo a ser seguido em caso de AEMB, pois 40\% dos alunos não conheciam, não sabiam ou não responderam. Esse resultado sugere mudanças para uma melhor divulgação e conhecimento do protocolo. Os resultados do estudo de Sasamoto ${ }^{15}$ e Pimentel et al $^{16}$, com graduandos de odontologia, também apontaram para a necessidade de maior divulgação de protocolo oficial sobre condutas pós-exposição e medidas preventivas.

Quando solicitada a avaliação dos alunos quanto ao conteúdo ministrado referente à biossegurança, prevenção de acidentes ou como proceder quando da ocorrência de um AEMB, 89,39\% dos alunos da IES(A) estavam satisfeitos ou muito satisfeitos, enquanto que $89,89 \%$ dos alunos da IES(B) estavam satisfeito ou pouco satisfeito. Os dados constatam uma maior insatisfação dos alunos da IES(B). 0 estudo de WU et $\mathrm{a}^{26}$ também demonstrou insatisfação dos alunos participantes, pois a maioria (80\%) afirmou que tinham conhecimento incompleto sobre infecções por exposição ocupacional.

Quando comparados os períodos da IES(A), foi observado no $5^{\circ}$ período maior prevalência de alunos que não sabiam a resposta quando perguntado sobre os patógenos que devem ser pesquisados após um AEMB. Na mesma questão foi constatado no $9^{\circ}$ período maior prevalência de alunos que responderam vírus da hepatite $\mathrm{A}$, o qual tem transmissão fecal-oral. As respostas evidenciaram que o conteúdo referente aos patógenos com possível transmissão após AEMB deve ser reforçado de forma mais abrangente em todos os períodos.

Na IES(B), a comparação por período, revelou no $8^{\circ}$ período maior prevalência da resposta (luvas de látex estéreis), quanto ao uso do EPI para a lavagem de instrumentos e equipamentos contaminados, evidenciando que o uso do EPI correto deve ser cobrado com maior rigor não apenas para os alunos iniciantes. Ainda na IES(B), quando perguntado se sabia da existência de um protocolo a ser seguido no caso de $\mathrm{AEMB}$, o $9^{\circ}$ período obteve a maior preva- 
lência de alunos que responderam não saber da existência de protocolo dessa natureza, o que revela que protocolos referentes ao AEMB e controle de infecção devem ser continuamente divulgados de forma participativa e em todos os períodos.

0 estudo apresenta como limitação o fato de ser um estudo transversal, cujos resultados podem se modificar na medida em que intervenções sejam implantadas. No entanto, por meio da metodologia empregada, foi possivel concluir, que há vulnerabilidade dos alunos de graduação em odontologia, quanto à exposição a material biológico potencialmente contaminado, no desempenho de suas atividades acadêmicas e que ambas as IES necessitam reavaliar suas ações referentes ao risco biológico e medidas preventivas. A IES(A) necessita rever o conteúdo que diz respeito às doenças infecciosas que podem ser transmitidas e seu modo de transmissão, como também os patógenos de maior transmissibilidade quando da ocorrência de um AEMB. A IES(B) deve priorizar a implantação de um comitê de biossegurança, a notificação, acompanhamento e a evolução das possíveis exposições, assim como difundir e manter protocolos atualizados. Outros aspectos que devem ser revistos são o uso regular e de forma correta do EPI, a necessidade da vacinação contra a hepatite B e a avaliação da imunidade após vacinação completa.

Parte considerável dos alunos apresenta déficits no conhecimento em relação à exposição a material biológico potencialmente contaminado, o que pode contribuir para condutas erradas e uma postura menos participativa na prevenção e gestão da pós-exposição. Confirma-se assim o fundamental papel das IES na formação dos futuros profissionais e da necessidade de reavaliar currículos, para que o conhecimento relacionado à saúde ocupacional esteja presente em todo o decorrer do curso.

Os dados apresentados abrem novos questionamentos e direcionam para outros estudos. Espera-se que este estudo proporcione subsídios para o planejamento e revisão de condutas e protocolos relativos à biossegurança e prevenção dos AEMB e possa contribuir para comparações entre outras instituições com características semelhantes.

\section{REFERENCIAS}

1. Kermode $M$, Jolley D, Langkham B, Thomas MS, Holmes W, Gifford SM Compliance with Universal/Standard Precautions among health care workers in rural north India. Am J Infect Control. 2005;33(1):27-33.

2. Brasil. Ministério da Saúde. Secretaria de Vigilância em Saúde. Recomendações para terapia III Tratamento, antirretroviral em adultos infectados pelo HIV-2008. Suplemento e prevenção. Brasilia: Ministério da Saúde; 2010.

3. Prüss-Üstün $A$, Rapiti $E_{1}$ Hutin $Y$. Sharps injuries:Global burden of disease from shaps injuries to healthcare workers [on line]. Geneva: WHO; 2003. p.39. Environmental burden of disease series, 3. [cited Jun 20 2014] Available from: http://www.who.int/quantifying_ehimpacts/publications/9241562463/en/

4. Centers for Disease Control and Prevention. Updated U.S. Public Health Service Guidelines for the Management of Occupational Exposures to HBV, HCV, and HIV and Recommendations for Postexposure Prophylaxis. MMWR Morb Mortal Wkly Rep. 2001 [cited June 21 2014]:1-42. Available from: http://www.cdc.gov/ MMWr/preview/mmwrhtml/rr5011a1.htm.

5. Brasil. Ministério da Saúde. Portaria No. 1.271 (6 jun 2014). Diário oficial da União. No.108, Seção 1:67-68.

6. Joyce MP, Kuhar D, Books JT. Occupationally Acquired HIV Infection Among Health Care Workers - United States, 1985-2013. MMWR Morb Mortal Wkly Rep. 2015; 63(53):1245-1246.

7. Brasil. Ministério da Saúde.Agencia Nacional de Vigilância Sanitária. Serviços Odontológicos: Prevenção e Controle de Riscos. ANVISA [on-line]. 2006 [acessado 22 Jun 2014]. Disponivel em: http://www.anvisa.gov.br/servicosaude/ manuais/manual_odonto.pdf.

8. Ribeiro P. Acidente com material biológico potencialmente contaminado em alunos de um curso de odontologia do interior do Estado do Paraná [dissertação] 2005. p. 150. São Paulo: USP Ribeirão Preto; 2005.

9. Zhang Z, Moji K, Cai G, Ikemoto J, Kuroiwa C. Risk of sharps exposure among health science students in northeast China. Biosci Trends [on line]. 2008 [cited Jun 2014];2(3):105-11. Available from: http://www.ncbi.nlm.nih.gov/ pubmed/20103912.

10. Ribeiro $P$, Hayashida M, Moriya T. Acidentes com material biológico entre estudantes de graduação em odontologia. Rev Odontol da Universidadade Cid S Paulo. 2007;19(3):263-268.

11. Bonis $M$ De, Costa $M$ da. Educação em biossegurança e bioética: articulação necessária em biotecnologia. Cien Saude Colet. 2009;14(6):2107-2114.

12. Pinelli C, Garcia PP, Campos JÁ, Dotta EA, Rabello AP. Biossegurança e Odontologia: crenças e atitudes de graduandos sobre o controle da infecção cruzada. Saúde e Soc. 2011;20(2):448-461.

13. Rahman B, Abraham SB, Alsalami AM, Alkhaja FE, Najem SI. Attitudes and practices of infection control among senior dental students at college of dentistry, university of Sharjah in the United Arab Emirates. Eur J Dent. 2013;7(Suppl 1):S15-9.
14. Wicker S, Rabenau HF. Occupational exposures to bloodborne viruses among German dental professionals and students in a clinical setting. Int Arch Occ Env Hea. 2010;83:77-83.

15. Sasamoto SA de A. Acidendes com material biológico em uma instituição de ensino odontológico: Perfil, notificação e sub-notificação [dissertação]. Goiânia: Universidade Federal de Goiás; 2008.

16. Pimentel MJ, Batista MM, Santos JP, Da Rosa MR. Biossegurança : comportamento dos alunos de Odontologia em relação ao controle de infecção cruzada Biosecurity : behavior of dental students in control of cross infection. Cad Saúde Colet. 2012;20(4):525-532.

17. Matsuda J, Grinbaum R, Davidowicz H. The assessment of infection control in dental practices in the municipality of São Paulo. Braz J Infect Dis. 2011;15(1):45-51.

18. Rapparini $C$, Reinhardt EL. Programa de prevenção de acidentes com materiais perfurocortantes em serviços de saúde. São Paulo: Fundacentro. Ministério do Trabalho e Emprego; 2010.

19. Rosental M, Weckwerth $\mathrm{PH}$, Chavasco JK. Risks of infection on odontological procedures. J Dent Oral Hyg. 2012;4(Dec):44-50.

20. Vasconcelos M, Brasil C da M V, Mota CCB, Carvalho NR de. Avaliação das normas de biossegurança nas clínicas odonto- lógicas da UFPE Evaluation of biosecutrity norms in UFPE dental clinics. Odontol Clín-Cientif. 2009;8(2):151156.

21. Orestes-Cardoso SM, Farias ABL, Pereira MR, Orestes-Cardoso AJ, Cunha I de F. Acidentes perfurocortantes : prevalência e medidas profiláticas em alunos de odontologia . Rev bras saúde ocup. 2009;34(119):6-14.

22. Machado-Carvalhais HP, Ramos-Jorge ML, Auad SM, Martins LHPM, Paiva SM, Pordeus IA. Management of Occupational Bloodborne Exposure in a Dental Teaching Environment. J Dent Educ. 2008;71(10):1348-1355.

23. Younai FS, Murphy DC, Kotelchuck D. Occupational Exposures to Blood in A Dental Teaching Environment: Results of a Ten-Year Surveillance Study. J Dent Educ. 2001;65(5):436-448.

24. Garcia L, Blank V. Prevalência de exposições ocupacionais de cirurgiõesdentistas e auxiliares de consultório dentário a material biológico Prevalence of occupational exposures to potentially infectious materials among dentists and dental assistants. Cad Saúde Pública. 2006;22(1):97-108.

25. Myers R, Larson E, Cheng B, Silva K Da, Kunzel C, Schwartz A. Hand Hygiene Among General Practice Dentists A Survey of Knowledge, Attitudes and Practices. J Am Dent Assoc. 2014;139:948-957.

26. Wu L, Yin Y-L, Song J-L, Chen Y, Wu Y-F, Zhao L. Knowledge, attitudes and practices surrounding occupational blood-borne pathogen exposure amongst students in two Chinese dental schools. Eur J Dent Educ. 2015;(Jul 16): [Epub ahead of print]. 